\title{
Review: non-parental daycare has short term and long term benefits for preschool children
}

\author{
Zoritch B, Roberts I. The health and welfare effects of day care for pre-school children: a systematic review of randomised controlled \\ trials. In: Cochrane Database of Systematic Reviews. The Cochrane Library. Oxford: Update Software, 1997: issue 4.
}

\section{Question}

What are the effects of out of home daycare on educational, health, and welfare outcomes for preschool children and their families?

\section{Data sources}

Studies were identified by searching Medline, Embase, Cochrane Controlled Trials Register, Social Science Citation Index, PsycLIT, ERIC, and BIRD databases; hand searching journals (1977-96); scanning bibliographies of relevant papers, books, reports, and conference proceedings; and contacting authors.

\section{Study selection}

Studies were selected if they included children $<5$ years of age who received non-parental day care and if they used randomised or quasi-randomised methods to allocate participants to groups.

\section{Data extraction}

Data were extracted on changes in children's developmental and intelligence quotients (IQ), school performance, behaviour, and health and on maternal employment, fertility, and interaction with children.

\section{Main results}

8 studies of disadvantaged populations in the US met the inclusion criteria. Compared with no daycare, daycare led to increased IQ at age 3 years (weighted mean difference [WMD] $14.4,95 \%$ CI 12.3 to $16.4,4$ studies) and at age 5 years (WMD 8.0, CI 5.8 to 10.2, 2 studies). Daycare also led to fewer children remaining in the same grade for 2 years and having special education classes (table). At 27 years old, those who were in daycare before 5 years of age were less likely to be arrested, receive welfare assistance, or give birth outside of marriage and were more likely to graduate from high school, be married, earn higher wages, and own a home than those who were not in daycare before the age of 5 years (1 study). The average number of reported health conditions was higher for children in daycare at age 3 years, but not at 5 years; rates of admission to hospital were similar ( 1 study). Mothers of children in daycare were more likely to be employed than mothers of children in control groups (3 of 4 studies). Teenage mothers of children in daycare were less likely to have more children than teenage mothers of children who were not in daycare ( 1 study). Children in daycare and their mothers communicated more than children who were not in daycare and their mothers (3 of 4 studies).

\section{Conclusions}

Studies on disadvantaged populations in the US show that out of home daycare before the age of 5 years benefits children's intelligence quotients, school performance, and behaviour. Long term benefits include higher socioeconomic status, fewer births outside marriage, and decreased criminal behaviour. Benefits for mothers include positive effects on employment, fertility, and interaction with children.

Daycare v no daycare for children $<5$ years of age*

\begin{tabular}{llllll}
\hline & \multicolumn{3}{c}{ Weighted event rates } & & \\
\cline { 3 - 4 } Outcomes & \multirow{2}{*}{$\begin{array}{l}\text { No of } \\
\text { studies }\end{array}$} & Daycare & Control & RRR (95\% CI) & NNT (CI) \\
\hline Grade retention & 5 & $27 \%$ & $37 \%$ & $36 \%(18$ to 51$)$ & $10(6$ to 37$)$ \\
Special education & 4 & $18 \%$ & $40 \%$ & $59 \%(39$ to 73$)$ & 5 (4 to 8) \\
\hline
\end{tabular}

*Abbreviations defined in glossary; RRR, NNT, and CI calculated from data in article

Source of funding: British National Health Service Research and Development Programme: Mother and Child Health.

For article reprint:Dr B Zoritch, St Peter's Hospital, Children's Unit, Guildford Road, Chertsey, Surrey KT16 OPZ, UK. Fax +44 (0)1932841683.

\section{Commentary}

This study by Zoritch and Roberts is a thorough attempt to systematically review randomised controlled trials (RCTs) that examine the effects of out of home daycare on children. The authors highlight the difficulty and controversy of applying such methods to social inquiry. They also acknowledge that the provision of, and attitude towards, out of home daycare varies greatly between Europe and North America. The diverse cultural and economic priorities placed on child welfare and family support in different societies make it difficult to produce generalisable data.

Because of the limited number of RCTs, Zoritch and Roberts point out that the findings should be treated with caution. All 8 studies used American populations; 6 focused only on low socioeconomic groups and 2 also in- cluded middle class families; and 7 focused on African-American communities. Five studies included home visiting and parental training as interventions in addition to daycare. These additional interventions may have led to changes in family life that contributed to the positive benefits reported and may account for the persistent difference between experimental and control groups long after IQ differences disappeared. Future research should include different populations; separate the effects of home visiting, parental training, and daycare; and use a range of education, health, and welfare outcomes.

The findings of this study will be of use to public health nurses, midwives, and nurses working in maternal child health or family nursing services. They add measured support to the view that out of home daycare (in conjunction with home visiting and targeted parental training) may have positive effects on children's development, school achievement, and adult life course. Nurses and midwives may use these findings to provide information in the antenatal and postnatal periods, to support home visiting and targeted parental training, and to work with local communities to provide out of home daycare services. These findings may also be used when working with single parents who are concerned that the economic benefits of employment may be offset by damaging effects of daycare on their children.

David Pontin, RN, PhD Senior Lecturer

Institute of Health Studies University of Plymouth Taunton, Somerset, $U K$ 